\title{
Methodology of teaching of design - creative manifestos
}

\author{
Elena Vasilenko, Pavel Vasilenko, and Anastasia Kondyukova
}

Moscow State University of Technology and Management named after K. G. Razumovsky (PKU), ul. Zemlyanoy Val, 73, 109004 Moscow, Russian Federation

\begin{abstract}
This article discusses the main manifestos of designers and theorists of the world, setting new trends in the methodology of education. The materials published in the 70s of the last century, which have not lost their relevance today, as well as modern materials in the field of design theory published in different countries of the world, are studied. The analysis of these sources allowed us to identify two groups of conditions and requirements for the new methodology of teaching design, the need for the formation of modern project thinking. One of them focuses the system on the idea of serving not advertising and industry that produces similar and even dangerous products, but something more valuable, durable and unique. As well as participation in solving important global problems. Another group forms the criteria for the nature of the educational process itself. It puts before us the need to choose methods of continuous, active education, integrate it into everyday life, saturate it with various creative technologies, points out the advantages of working in a team and calls for a constant rethinking of the past experience, both of all mankind and of an individual artist-designer. A methodology based on such requirements is being developed and used in the modern world. All this speaks of changes in the teaching of design, the creation of certain pedagogical conditions that play an important role in the development of design around the world.
\end{abstract}

\section{Introduction}

Design as a separate field of activity or type appeared relatively recently, at the turn of the XIX-XX centuries. The reason for this was the separation of its functions and goals from simple industrial design and applied artistic activity. The question of what exactly is the purpose of design was raised by specialists throughout the XX century and answered it with their manifestos. Based on this information, the best design schools formed their own system of training, developing creativity to meet the needs of the global community. The modern mission of design puts forward certain criteria for choosing a methodology for training designers, for the formation of project thinking, which will meet the requirements of the time.

The aim of the research is an analytical study of the main design manifestos of the 1970s-2020s. And the determination of the main requirements for the methodology of modern design training based on the results obtained. 


\section{Materials and Methods}

The main methods for research in the first stage are the scientific analysis necessary to identify the main goals of design in the modern world. And such methods as comparison, observation, the search for analogies, descriptions served as the basis for the second stage of the study - to identify the needs of society to the teaching methodology. The materials for the study were theoretical concepts, scientific literature, and manifestos.

\section{Results and Discussion}

Already in the second half of the XX century, the economic, political and environmental situation in the world raised many questions for designers. And to answer them, it required a modernization of the very thinking that underlies design. Ken Garland's 1964 manifesto "First Things First" is a protest to the society of advertising and consumption, a call to be cleansed of the information impact on a person. It was re-published in 1999, the text of the new version did not differ from the previous one, which indicates that the design community has not reacted with actions to the words over the past half century. The manifesto expresses an opinion about the current situation. Together with the increase in population, we have reached a saturation point where the ringing cry of sales has turned into an unintelligible noise. We believe that there are other things more worthy of our skills and our experience. This is the main message-to stop wasting original abilities in the service of advertising, the same producers, short-term graphics. It's the desire to invest them in something more worthwhile: "There are road and street signs, books and magazines... through which we promote our craft, our education, our culture, and our considerable awareness of the world" [1].

The 1968 article "The Decline of Industrial Design" in the American magazine Fortune echoed this message: "Designers are engaged in the practical design of what already exists. They have almost completely switched to advertising, product packaging, marketing consulting, and corporate image creation" [2]. A kind of manifesto was the words of Viktor Papanek, published as the preface to his book "Design for the real world" (1970). He raises the problem, already described by his contemporaries to the level of absurdity, in order to strengthen the impact on the reader. There are more harmful professions than industrial design, but there are very few of them. And perhaps only one profession surpasses him in the degree of fraud -advertising design. Convincing people to buy something they don't need with money they don't have, in order to impress those who don't care, is now a masterly fraud.

Describing the situation, the author also touches on the problem of ecology and the issue of teaching design. By designing criminally unsafe cars that kill or maim up to a million people a year around the world, creating new types of garbage that clutter and disfigure landscapes, and advocating the use of materials and technologies that pollute the air we breathe, designers are becoming truly dangerous people. Moreover, they diligently teach young people all the skills inherent in this profession [3]. The manifestos listed above can be attributed to the first semantic group that forms the requirements for modern training of specialists:

- the focus of education on the contemporary global queries and concerns;

- the contribution of creative resources to the creation of something lasting, consistent with universal values;

- work only on a high-quality, safe product;

- contribution to uniqueness, innovation, and not the creation of standard things and services under a new cover for a visible expansion of the offer. 
Another group of manifestos, emphasizes not so much the goal of training designers, but rather describes the tools to be followed in achieving this goal. It includes Bruce Mau's "Incomplete Manifesto for Creative Growth" published in International Design Magazine (translated from the publication: Bruce Mau's "An incomplete Manifesto for Growth"). All 43 rules described by him are aimed at expanding creative freedom of expression. An example would be the following:

- $\quad$ "Love your experiments (like an ugly child)"

— _ "Generate ideas"

- $\quad$ "Ask stupid questions" [4].

These and other rules can be used to rethink the established system of education that has developed over the twentieth century. Bruce Mau felt, like many others, that classical learning was no longer in line with society's demands, although it was still an option with less resistance [5]. After analyzing all the postulates of the Bruce Mau manifesto, you can draw up the following requirements for a new methodology for teaching design:

1.In the first place is the creative process itself, free from the division into "good and bad", "right and wrong", "fashionable and outdated", "error and victory".

2. The nature of training is active, continuous: deepening, research, generating ideas, asking questions, repeating, going out, making mistakes.

3. The new methodology should involve the mutual integration of the creative process and human life, for a deeper understanding of the processes and open creativity.

4. Constant work with other people, leading to both a synthesis of ideas, and healthy self-esteem, as well as reasonable competition - a catalyst for development.

5.It is assumed that the student can be creative at three levels: the level of creating a design object, the level of creating tools and ways to achieve results, the level of creating a methodology that stands above the entire learning and design process.

6. Use of past experience: universal, nearby people, competitors, your own. Learning in an open system, the ability to listen, to imitate, to look with a new eye at the chaos of failed ideas.

7. The use of technologies and electronic programs to serve the creative process and the development of mental and physical skills of the student, and not to replace them, implying the subsequent degradation of abilities.

8. Acceptance of the conditions and requests of the system, society, and the environment for which the design works.

9. Develop not only creative skills, but also the ability to destroy, break, invert, and improvise.

A kind of manifesto, similar in ideas to the rules of Bruce Mau, are the" commandments " of Karim Rashid, one of the most famous modern representatives of the design elite [6]. First of all, after analyzing its principles, you can see that it also speaks about the fusion of life and creative activity - do not limit your opportunities to a narrow specialization, specialize in life as a whole. And moreover, it equates the very meaning of human existence with the possibility of creating: "Remember: to be means to create." In addition to advice on the creative process and lifestyle, Karim Rashid touches on the issue of mass production, which was raised in manifestos back in the 1970s, he writes: "Before you create something material, ask yourself if there is any value or original idea in what you are going to do" [7]. And also draws attention to the fact that it is the quality and value of the product that should make advertising, and not artificially the opposite: "It is not the brand that creates the products, but the products that create the brand" [8]. Thus, using the example of this outstanding designer, we can see how strongly the new mission of design design, formed in the last century, resonates in the modern world [9]. The rules described by Bruce Mau echo the Design Thinking methodology, which was created and developed by the founders of 
IDEO and is now taught in leading foreign universities. David Kelly, one of the teachers and theorists of this system, said the following:

"We teach Design thinking and innovation methodologies aimed at creating highpotential professionals who, acting as agents of change, deal with topical issues... Our process leads to a clear distinction between "doing the right thing" and " doing the right thing." We focus on creative management competencies combined with high-level strategic thinking and material decisions, whether they are products, services, or events that have a significant impact on human lives... " [10].

The "Design Thinking" system focuses on postulates similar to what Bruce Mau described in his manifesto. It uses a large number of tools aimed at expanding creative and logical thinking, continuous generation of ideas, integration of methods and experience of other spheres of life into design design, etc [11]. Thus, the "Design Thinking" methodology not only serves as an example of a system that meets the needs of modern education, it itself forms the requirements and ideology of a new education designed to nurture experienced, creative professionals whose minds are turned to serving humanity and solving pressing global problems [12].

\section{Conclusion}

Based on the conducted research, we can draw the following conclusion about the necessary requirements that the world community imposes on modern methods of teaching design in design. These requirements can be divided into two groups. The first is an understanding of the new mission of design, the orientation of the entire ideological part of the methodology and its constituent methods to its service $[13,14]$. It should be understood that while training is still moving along a given trajectory, and the manufacturer is still paying for high-quality advertising and selling design, environmental, economic and political situations require that creativity focus on the global problems of the world. It is necessary to contribute to the creation of something long-lasting, strengthening universal values, in unique, innovative and safe products [15]. And moreover, by closing this chain, educating an increasing number of people in the ideas and values of a new culture that can become a way out of the global crisis.

On the other hand, along with these values, certain requests are formed to the nature of the learning process itself. The manifesto of Bruce Mau, the commandments of Karim Rashid and systems like "Design Thinking" say that education should go to its goal in new ways. First of all, they should be aimed at continuous learning, integrated into a person's life and intersecting with other areas [16]. Focus on the process, not the result, with acceptance of the whole experience, without a critical division into "good and bad". The ability to process information both at the level of synthesis and at the level of destruction. Creativity in contact with people, the ability to use the past experience of all mankind, as well as your own. All these recommendations lead to the creation of a new teaching methodology aimed at changing the future culture of the world through design.

\section{References}

1. E.V. Lopasova, Professional competence of a modern teacher, 134 (2016)

2. V.R. Aronov, Design problems-5, 318 (2009)

3. E.V. Vasilenko, P.G. Vasilenko, A.I. Fursov, Modern Science, 9(2), 137 (2019)

4. E.V. Lopasova, Theory and practice of social development, 10, 137 (2012) 
5. M.M. Mikheeva, Modern methods in design: on the course "Fundamentals of theory and methodology of design in industrial design", 104 (2012)

6. V. Papanek, Design for the real world, 416 (2004)

7. E.V. Vasilenko, V.V. Muradova, Yu.S. Mareeva, Features of the methodology of teach ing young people digital technologies design panoramas, 92 (2020)

8. K. Rashid, I want to change the world, 250 (Columbia: "Daedalus books", 2001)

9. S.N. Begidova, P.G. Vasilenko, Bulletin of the Adygeya State University, 3, 15 (2016)

10. Adbusters, the AIGA journal fall 1999 / spring 2000 (1999)

11. M. Bruce, An incomplete Manifesto for Growth, 88 (London: "Phaidon", 2000)

12. E. Vasilenko, P. Vasilenko, N. Saenko, V. Borysov, S. Borysova, I. Prodan, Internation al J. of Engineering Research and Technology, 13, 96 (1990)

13. V.M. Chubarov, Materials of the all-Union Seminar, 5, 42 (2009)

14. Fine art in school, 4 (2019)

15. E.V. Fomina, N.I. Barsukova, Interciencia, 4 (2019) 